\title{
Impact of filler size and distribution on roughness and wear of composite resin after simulated toothbrushing
}

\author{
Gabriela Ulian de OLIVEIRA ${ }^{1}$, Rafael Francisco Lia MONDELLI², Marcela CHARANTOLA RODRIGUES ${ }^{1}$, Eduardo \\ Batista FRANCO ${ }^{3}$, Sérgio Kiyoshi ISHIKIRIAMA ${ }^{4}$, Linda WANG ${ }^{2}$
}

\begin{abstract}
1- DDS, MSc, Department of Operative Dentistry, Endodontics and Dental Materials, Bauru School of Dentistry, University of São Paulo, Bauru, SP, Brazil. 2- DDS, MSc, PhD, Associate Professor, Department of Operative Dentistry, Endodontics and Dental Materials, Bauru School of Dentistry, University of São Paulo, Bauru, SP, Brazil.

3- DDS, MSc, PhD, Full Professor, Department of Operative Dentistry, Endodontics and Dental Materials, Bauru School of Dentistry, University of São Paulo, Bauru, SP, Brazil.

4- DDS, MSc, PhD, Assistant Professor, Department of Operative Dentistry, Endodontics and Dental Materials, Bauru School of Dentistry, University of São Paulo, Bauru, SP, Brazil.
\end{abstract}

Corresponding address: Prof. Dr. Rafael Francisco Lia Mondelli - Faculdade de Odontologia de Bauru - USP - Departamento de Dentística, Endodontia e Materiais Odontológicos - Alameda Dr. Otávio Pinheiro Brizola, 9-75 - Bauru - São Paulo - Brazil - Caixa Postal 73 - $17012-901$ - Bauru - SP - Brazil - Phone: 551432358263 - Fax: 551432261495 - e-mail: rafamond@fob.usp.br

Received: November 5, 2010 - Modification: August 5, 2011 - Accepted: September 5, 2011

\section{ABSTRACT}

\begin{abstract}
$\mathrm{O}$ bjectives: Nanofilled composite resins are claimed to provide superior mechanical properties compared with microhybrid resins. Thus, the aim of this study was to compare nanofilled with microhybrid composite resins. The null hypothesis was that the size and the distribution of fillers do not influence the mechanical properties of surface roughness and wear after simulated toothbrushing test. Material and methods: Ten rectangular specimens (15 mm x $5 \mathrm{~mm} \times 4 \mathrm{~mm}$ ) of Filtek Z250 (FZ2), Admira (A), TPH3 (T), Esthet-X (EX), Estelite Sigma (ES), Concept Advanced (C), Grandio (G) and Filtek Z350 (F) were prepared according to manufacturer's instructions. Half of each top surface was protected with nail polish as control surface (not brushed) while the other half was assessed with five random readings using a roughness tester ( $\mathrm{Ra}$ ). Following, the specimens were abraded by simulated toothbrushing with soft toothbrushes and slurry comprised of 2:1 water and dentifrice (w/w). 100,000 strokes were performed and the brushed surfaces were reanalyzed. Nail polish layers were removed from the specimens so that the roughness (Ra) and the wear could be assessed with three random readings $(\mu \mathrm{m})$. Data were analyzed by ANOVA and Tukey's multiple-comparison test $(a=0.05)$. Results: Overall outcomes indicated that composite resins showed a significant increase in roughness after simulated toothbrushing, except for Grandio, which presented a smoother surface. Generally, wear of nanofilled resins was significantly lower compared with microhybrid resins. Conclusions: As restorative materials suffer alterations under mechanical challenges, such as toothbrushing, the use of nanofilled materials seem to be more resistant than microhybrid composite resins, being less prone to be rougher and worn.
\end{abstract}

Key words: Composite resins. Toothbrushing. Roughness. Wear.

\section{INTRODUCTION}

Material properties and technical approaches are two essential factors that have developed together over time in order to allow for a better clinical performance of composite resin restorations ${ }^{2,10,14,18}$.

Composite resins are so far the most esthetic restorative material applied in direct restorations ${ }^{2,14,18}$. Filler and organic matrix have been modified in an attempt to offer satisfactory mechanical and esthetic characteristics, thus allowing its indication to posterior teeth $2,7,10,11,12,14,18,20-22$. In this sense, nanotechnology has been applied to Dentistry, permitting the incorporation of a larger amount of small-sized filler particles in a more homogeneous 
distribution into organic matrix $x^{5,6,15}$.

The decreasing filler size over the years resulted in some changes in commercial composites, resulting in different implications to their adequate clinical use and perspectives of success. Since the introduction of nanotechnology, these resins (0.1-100 $\mu \mathrm{m})$ are classified as Nanohybrid, NanoMicrohybrid, Microybrid, Microfilled ${ }^{10,19}$. This classification varies extensively according to manufacturers and cannot be precisely identified $5,6,10,15$. This scenario pointed out to the need for investigating optical and mechanical properties of this new generation of composite resins. As fillers play a major role to reflect the irradiated light, enhanced esthetic properties were previously verified ${ }^{13,15}$. A perspective of improved material is also expected as high mechanical properties are attributed to filler load ${ }^{23}$. However, it should be highlighted that the particles are not arranged in the same pattern to all nanotechnology materials. There are composites with nanofillers, nanoclusters and/or microhybrid particles that are combined in different structures $5,6,10,15$. Additionally, a larger surface area of particles with reduced filler size result in a material more prone to water uptake, which can affect negatively its mechanical properties by degradation ${ }^{8-10}$. It is believed that as silane-based fillers are susceptible to hydrolytic degradation, it may affect adversely their dynamic mechanical properties over time ${ }^{9,22}$.

Surface roughness and wear tests after simulated toothbrushing have been indicated to assess the mechanical features of restorative materials $3,4,8,20,25$. Simulated toothbrushing can intentionally provoke a stress in the organic matrix, fillers and their interfaces, and adhere to an assessment of their resistance properties ${ }^{16}$.

As fillers are incorporated into the organic matrix by a chemical treatment of their surfaces, this interface can be stressed and be loosened from the matrix in different patterns ${ }^{17}$. Through a threebody abrasive action, toothbrushing provokes a mechanical challenge. In consequence, these particles can be loosed, fractured or the organic matrix can be removed, exposing the particles. Thus, roughness and wear readings can establish a comparison of the performance of these materials.

The aim of this study was to compare mechanical performance of nanotechnology high-density composite resins, according to their dimensions and distribution. The null hypothesis is that there is no difference of their performance on surface roughness and wear assessments after simulated toothbrushing testing.

\section{MATERIAL AND METHODS}

\section{Experimental design}

This in vitro study was performed involving two factors: material (in eight levels) and time (in two levels). The quantitative response variables were the surface roughness and wear analyzed by profilometry $(\mu \mathrm{m})$. Information about materials under investigation is presented in Figure 1.

Ten specimens of each material were prepared using a previously lubricated steel stainless mold of $15 \mathrm{~mm}$ length $\times 4 \mathrm{~mm}$ in width $\times 5 \mathrm{~mm}$ in height placed over a glass slab and polyester strip (TDV Dental LTDA, Pomerode, SC, Brazil). Four individual increments were inserted which were light-cured according to manufacturers' recommendations, using a halogen lamp VIP (VIP, Bisco Inc, Schaumburg, IL, USA), with irradiance of $600 \mathrm{~mW} / \mathrm{cm}^{2}$, as measured with a curing radiometer (Curing Radiometer - Model 100P/N150503, Demetron Research Corp., Danbury, CT, USA). The final increment was pressed with a polyester strip (TDV Dental LTDA, Pomerode, SC, Brazil) and glass slab under a constant axial load of $500 \mathrm{~g}$ for $30 \mathrm{~s}$. Regardless of the recommended time, the last increment of all composite resins was light-cured for $40 \mathrm{~s}$ to standardize the surface. The specimens were removed from the molds and the excess was cut off with a \#12 Bard-Parker scalpel blade.

Thereafter, the specimens were subjected to mechanical polishing in a metallographic polishing machine (Arotec - APL 4, Arotec SA Ind. Com., Cotia, SP, Brazil) using the sequence of \#600-, \#800- and \#1200-grit silicon-carbide abrasive papers under water-cooling. Polishing was performed under a load of $172 \mathrm{~g}$ for $20 \mathrm{~s}$ for each granulation. All specimens were ultrasonically cleaned in deionized water for $10 \mathrm{~min}$ and were identified and stored at $37^{\circ} \mathrm{C}$ for 1 week.

In order to allow wear analysis, each specimen had half of its surface protected with two layers of nail polish that served as control (with no abrasion).

Baseline surface roughness of the specimens was analyzed by a profilometer (Hommel Tester T1000, Hommelwerke GmbH, VillingenSchwenningen, Germany) accurate to $0.01 \mu \mathrm{m}$ and was expressed in $\mu \mathrm{m}$ as a Ra value. Five records of each specimen were randomly assessed. To record roughness measurements of the surfaces a device containing a diamond needle affixed to the profilometer was used. The average of five randomized transversal readings was established as the baseline roughness value. Ra range was previously adjusted at 0.01 to $0.8 \mu \mathrm{m}$ at a cut-off of $0.25 \mathrm{~mm}$. Readings were obtained from 4.8-mmlong measurements. 
A specially designed toothbrushing machine was used for the test. It allowed controlled performance using soft nylon bristle toothbrush heads (Colgate Classic, Colgate-Palmolive Ind. Com. Ltda, São Paulo, SP, Brazil) under a load of $300 \mathrm{~g}$ and temperature of $37^{\circ} \mathrm{C}$. Slurry was prepared according to ISO specification \#145691 , mixing 2:1 of deionized water and dentifrice (Colgate Total 12, Colgate-Palmolive Ind. Com. Ltda, São Paulo, SP, Brazil) and $0.4 \mathrm{~mL}$ amount was injected periodically to renew for fresh slurry. For each specimen, a total of 100,000 strokes were performed and toothbrushes were replaced after 50,000 strokes. At the end of the test, each specimen was rinsed under running water and cleaning was completed by sonicating in deionized water for $10 \mathrm{~min}$.

Final roughness was analyzed in the same way as described for baseline. Differences between initial and final readings were registered. For wear assessment, the same profilometer was used; allowing a needle to run from the protected half (control) to the abraded half. Parameters were adjusted to tolerances from 0 to $40 \mu \mathrm{m}$, length of assessment at $4.8 \mathrm{~mm}$ and cut off of $0.25 \mathrm{~mm}$. The mean values among three readings were registered for each specimen.

Random samples of each tested groups, before and after toothbrushing, were selected for microscopic examination to illustrate possible events. These specimens were prepared and mounted on metal stubs, sputter coated with

\begin{tabular}{|c|c|c|c|c|}
\hline Material & Manufacturer & Classification & Monomer/Filler & $\%$ w/v \\
\hline Filtek Z250 & $\begin{array}{c}\text { 3M ESPE, St Paul, MN, } \\
\text { USA }\end{array}$ & Microhybrid & $\begin{array}{l}\text { Monomers: Bis-GMA, UDMA, Bis-EMA } \\
\text { Filler: Zircon and } \mathrm{SiO}_{2}-0.6 \mu \mathrm{m}(0.01 \text { - } \\
\quad 3.5 \mu \mathrm{m})\end{array}$ & $84.5 / 60$ \\
\hline Admira & $\begin{array}{c}\text { Voco, GmbH, Cuxhaven, } \\
\text { Germany }\end{array}$ & Microhybrid & $\begin{array}{l}\text { Monomers: Ormocer, Additive aliphatic } \\
\text { and aromatic dimethacrylate } \\
\text { Filler: Glass ceramic } \mathrm{SiO}_{2} \text { - (mean of } \\
0.7 \mu \mathrm{m})\end{array}$ & $78 / 56$ \\
\hline TPH3 & Dentsply, York, PA, USA & Nanohybrid & $\begin{array}{l}\text { Monomers: Bis-GMA; BisEMA } \\
\text { Filler: Barium aluminium borosilicate } \\
\text { glass, Fluoro-aluminium borosilicate } \\
\text { glass, Silica - }(0.02-1 \mu \mathrm{m})\end{array}$ & $75 /^{*}$ \\
\hline Estelite Sigma & $\begin{array}{l}\text { Tokuyama Dental } \\
\text { Corporation, Japan }\end{array}$ & NanoMicrohybrid & $\begin{array}{c}\text { Monomers: Bis-GMA/ TEGDMA } \\
\text { Filler: Spherical silica/zirconia } \\
\text { submicron filler - } 0.2 \mu \mathrm{m}(0.1 \mu \mathrm{m}-0.3 \\
\mu \mathrm{m})\end{array}$ & $82 / 71$ \\
\hline Esthet-X & Dentsply, York, PA ,USA & Microhybrid & $\begin{array}{l}\text { Monomers: Bis-GMA, BisEMA, } \\
\text { TEGDMA } \\
\text { Filler: Silanized Fluoro-aluminium } \\
\text { borosilicate glass, silanized barium }(1 \\
\mu \mathrm{m}) \text { and colloidal silica }(0.04 \mu \mathrm{m})\end{array}$ & $77 / 60$ \\
\hline Concept Advanced & $\begin{array}{c}\text { Vigodent S/A Produtos e } \\
\text { Comércio, Rio de Janeiro, } \\
\text { RJ, Brazil }\end{array}$ & Nanofilled & $\begin{array}{l}\text { Monomers: Bis-GMA/UDMA } \\
\text { Filler: Alluminium and barium silicate - } \\
0.04 \mathrm{~mm}(0.001-2 \mu \mathrm{m})\end{array}$ & $77.5 /^{*}$ \\
\hline Grandio & $\begin{array}{c}\text { Voco, GmbH, Cuxhaven, } \\
\text { Germany }\end{array}$ & Nano-hybrid & $\begin{array}{c}\text { Monomers: Bis-GMA, TEGMA } \\
\text { Filler: glass ceramic filler }(1 \mu \mathrm{m}) \text { and } \\
\mathrm{SiO}_{2}(20-60 \mathrm{~nm})\end{array}$ & $87 / 71.4$ \\
\hline Filtek Z350 & $\begin{array}{c}\text { 3M ESPE, St Paul, MN, } \\
\text { USA }\end{array}$ & Nanofilled & $\begin{array}{l}\text { Monomers: Bis-GMA, UDMA, } \\
\text { TEGDMA, Bis-EMA } \\
\text { Filler: aggregated zirconia }(0.6-1.4 \\
\mu \mathrm{m}) \text { and } \mathrm{SiO}_{2}(20 \mathrm{~nm})\end{array}$ & $78.5 / 59.5$ \\
\hline
\end{tabular}

All informations were supplied by the manufacturers

${ }^{*}$ Not informed by manufactures

Bis-GMA=bisphenol-A-glycidyl methacrylate; Bis-EMA=bisphenol-A-ethoxylate glycidyl methacrylate; Bis-PMA=bisphenolA-polyethylene glycoldiether dimethacrylate; TEGDMA=triethylene glycol dimethacrylate; UDMA=urethane dimethacrylate

Figure 1- Information of tested composite resins 
gold, and examined under a scanning electron microscope (JSM T220A, JEOL Ltd., Peabody, MA, USA) at 500x magnification.

The assumptions of equality of variances and normal distribution of errors were checked for the tested response variables. Since the assumptions were satisfied, data were subjected to oneway ANOVA and Tukey's post-hoc test for the comparison of initial and final roughness and wear among the materials. Paired t-test was applied for roughness analysis considering a two-time evaluation $(p<0.05)$.

\section{RESULTS}

Comparative roughness assessments and wear values after simulated toothbrushing are presented in Table 1. For all composite resins, initial and final roughness was statistically different $(p<0.05)$.

Comparison among the tested materials regarding their initial roughness, showed that the nanofilled resins, Filtek Z350 and Concept Advanced, as well as the microhybrid resins, Admira and Estelite Sigma, presented smoother surfaces while Filtek Z250, TPH3, and Esthet X presented rougher surfaces.
According to the final condition, roughness outcomes revealed a great variability of performance after simulated toothbrushing. Admira, Grandio, Filtek Z350 and TPH3 were less rougher than the other composite resins. Concept and Esthet $X$ were more susceptible to abrasion, consequently, presented significantly higher roughness. Intermediate values were found for Filtek Z250 and Estelite Sigma. According to the presented results, the qualitative analysis of the SEM micrographs of the resins, after the abrasion test, showed more polished surface of the nanofilled and the nanohybrid resins than the microhybrid resins, as seen in Figure 2.

Comparing each system before and after toothbrushing simulation, except for Grandio, all materials became significantly rougher than their initial condition $(p<0.05)$.

The wear assessment values revealed that Admira, Grandio and Filtek 2350 were less susceptible to wear after toothbrushing simulation, followed by TPH3, Estelite Sigma and Esthet $X$. Concept and Filtek $\mathrm{Z} 250$ presented the least resistance to wear $(p<0.05)$.

Table 1- Mean and standard deviation of initial surface roughness (Ra), final surface roughness (Ra) and wear after simulated toothbrushing $(\mu \mathrm{m})$

\begin{tabular}{cccc}
\hline Material & Initial roughess & Final roughness & Wear \\
\hline FZ2 & $0.08 \pm 0.01^{\mathrm{Ac}}$ & $0.19 \pm 0.04^{\mathrm{Bbc}}$ & $14.6 \pm 4.39^{\mathrm{d}}$ \\
$\mathrm{A}$ & $0.05 \pm 0.00^{\mathrm{Aa}}$ & $0.06 \pm 0.02^{\mathrm{Ba}}$ & $3.17 \pm 1.16^{\mathrm{a}}$ \\
\hline$T$ & $0.08 \pm 0.01^{\mathrm{Ac}}$ & $0.18 \pm 0.10^{\mathrm{Bab}}$ & $8.02 \pm 2.51^{\mathrm{bc}}$ \\
ES & $0.05 \pm 0.01^{\mathrm{Aa}}$ & $0.30 \pm 0.08^{\mathrm{Bbc}}$ & $11.75 \pm 3.32^{\mathrm{cd}}$ \\
EX & $0.06 \pm 0.01^{\mathrm{Ab}}$ & $0.47 \pm 0.15^{\mathrm{Bd}}$ & $12.61 \pm 4.26^{\mathrm{cd}}$ \\
C & $0.05 \pm 0.01^{\mathrm{Aab}}$ & $0.51 \pm 0.17^{\mathrm{Bd}}$ & $13.26 \pm 5.29^{\mathrm{d}}$ \\
G & $0.08 \pm 0.01^{\mathrm{Ac}}$ & $0.07 \pm 0.01^{\mathrm{Ba}}$ & $4.27 \pm 1.80^{\mathrm{ab}}$ \\
FZ3 & $0.04 \pm 0.06^{\mathrm{Aa}}$ & $0.13 \pm 0.05^{\mathrm{Bab}}$ & $5.58 \pm 1.46^{\mathrm{ab}}$ \\
\hline
\end{tabular}

Different capital letters indicate differences between columns

Different lower case letters indicate differences between rows

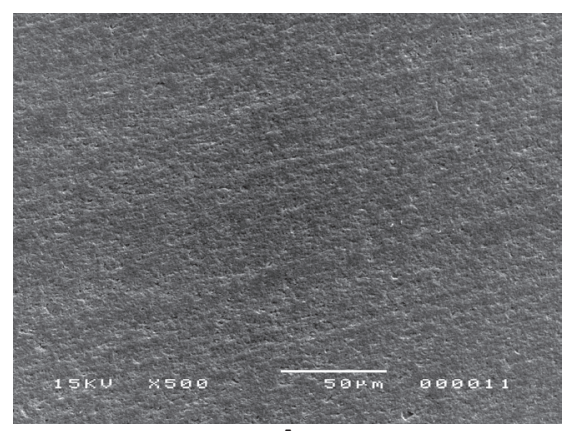

A

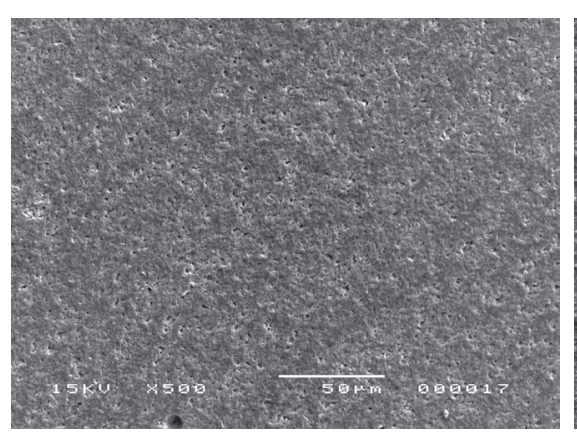

B

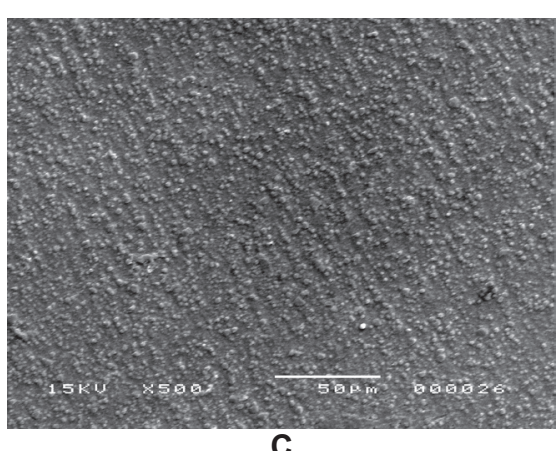

C

Figure 2- Qualitative analyzis of different composite resins after abrasion test. A - Nanofilled (Esthet X); B - Nanohybrid (TPH3); C - Microhybrid (Z250) 


\section{DISCUSSION}

Enamel and dentin are directly affected by caries disease. When these tissues are compromised, teeth lose the ability to absorb the load from mechanical impact. Dentin presents a mechanical property from a complex arrangement of collagen type-I-fibrils reinforced with a nanocrystalline apatite mineral in the extra and intrafibrilar spaces ${ }^{1}$. However, when caries affects dentin, it results in a disorganized structure. Thus, when this natural complex is changed, the restorative material needs to present properties that are able to recover it an appropriate manner. In order to reach a satisfactory clinical performance, the composite resin is indicated as a hybrid material composed mainly by fillers and organic matrix. Thus, mechanical properties are of great interest to allow composite resins to be well indicated ${ }^{10,19}$.

Filler particles play an important role in this mechanism. They are responsible for the strength of the material and also protect organic matrix from wear $8,17,25$. Nanotechnology provides incorporation of well-distributed and larger amount of fillers compared with other categories ${ }^{5,6,15}$. Consequently, a high mechanical resistance is expected. This is essential in posterior restorations ${ }^{2,14,18}$.

Organic matrix is the second point of interest to be focused. There have been several investigations with the purpose to promote modifications to reach better properties ${ }^{10}$. This balance of organic matrix and fillers is responsible for the determination of long-term clinical use ${ }^{2,14}$.

Therefore, the comparison of the performance of resin-based materials is an essential parameter to aid clinical indication. Roughness is well accepted as a comparative feature. Basically, it quantifies surface texture by means of randomized readings of the amplitudes in $\mathrm{mm}$, established as Ra (arithmetical roughness) 3,8,20,25.

According to the results of the present study, simulated toothbrushing was a mechanical process able to modify the balance between organic matrix and filler since all composite resins showed rougher surface after the abrasion challenge as shown in Table 1.

Initial roughness is essential to establish a parameter of comparison. Filtek Z350 and Concept Advanced presented the smoothest surfaces. This was somehow expected as they are categorized as nanofilled resins. Nanofilled materials have the ability to provide more volume of filler in homogeneous distribution, which enables it to protect organic matrix wear ${ }^{3,23}$.

Admira and Estelite were significantly rougher than the nanofilled composite resins. The possible explanation relies on the fact that Admira, even classified as a microhybrid composite, is composed differently than other tested resins as its monomers are based on Ormocer, which is considered a resistant organic matrix ${ }^{10}$. Long-term clinical studies have shown the superiority of this matrix regardless of the size of filler ${ }^{2,14}$. In occlusal stress-bearing cavities, the Ormocer-based composite materials tested performed comparably to conventional microhybrid Bis-GMA-based composites. This study reveals that this organic matrix itself is more resistant than conventional monomers. On the other hand, the manufacturer of Estelite classifies it as nanomicrohybrid material. Since the variability between nano-sized materials also includes their distribution, it might affect their performance in a not well-clarified manner. It requires more investigation.

Filtek Z250, TPH3 and Grandio were the materials that exhibited rougher initial values. Filtek $Z 250$ is a microhybrid resin while the manufacturers classify TPH3 and Grandio as nanohybrid. Also, it is should be highlight that even Filtek Z250 and Esthet $X$ are both microhybrid, they differed statistically from each other. Despite this same categorization, it might vary in different levels that are not possible to precise, as their manufacturers do not supply this information in details. In comparison with the other tested materials, the distribution of the particles in hybrid resins is less homogeneous, which allows this condition. Additionally, the range of fillers of nanohybrid resins is large.

When final roughness was analyzed, distinct performances were observed after simulated toothbrush testing. Except for Grandio, all resins became rougher after toothbrushing, but Admira, Grandio, Filtek Z350 and TPH3 were less prone to be rougher. Once again, the organic matrix composition of Admira seemed to determine a good performance. Filtek Z350 as nanofilled material attended the expectation of this technology, confirming previous results ${ }^{9}$. Likely, toothbrushing abrasion caused a polishing effect on the surface, allowing smother surface compared with other resins, even rougher than its initial condition. Concept and Esthet $X$ were more susceptible to abrasion in terms of roughness as they presented the greatest values after the test. Concept is categorized as a nanofilled composite resin and its organic matrix is based on conventional BisGMA. Limited information is supplied by its manufacturer, and so, with the limitations of this study, we cannot confirm precisely the reason of this poor performance. Esthet $X$, on the other hand, as a microhybrid resin, was rougher as expected, compared with nanosized resins. Intermediate final roughness values were detected in Filtek Z250, TPH3 and Estelite Sigma. As these materials are classified as micro or nanohybrid materials, their 
performances are similar according to a previous study, which stated that they are both resistant materials ${ }^{10}$.

According to wear values, Admira was the least susceptible to wear after toothbrushing simulation. The specific performance of this Ormocer-based material seems to confirm the relevance of organic matrix as well as fillers.

Grandio and Filtek Z350 did not differ significantly from Admira. Once again, nanofilled materials also attest to the relevance of a combination of reduced size with homogeneous distribution of filler to reach satisfactory performance. In sequence, TPH3, Estelite Sigma and Esthet $X$ showed moderate resistance to wear. Concept and Filtek $\mathrm{Z} 250$ were the resins that had the high level of wear. As also stated, the poor results and lack of information about the organic matrix composition of Concept makes this resin less reliable.

Manufacturers have produced composites with different filler sizes (ranging from 5 to $100 \mathrm{~nm}$ ) and distributions, in order to enhance performance. The mechanical properties like high flexural strength, low abrasion, low polymerization shrinkage and resistance to fracture are attributed to the high-filler load of these materials because of the small size the fillers possess ${ }^{21}$. An explanation for the improvement of the wear resistance with the smaller particles is that the mean distance between neighboring particles was smaller than that with the coarsest filler particles ${ }^{24}$. This size and distribution is favorable to protect organic matrix against wear, resulting in greater durability. From the observations of Admira, it can be stated that the Ormocer-based composite is relevant to resist wearing and roughness changes, which is comparable to the performance of the nanofilled composite resins compared with the other tested materials.

\section{CONCLUSIONS}

With the limitations of this study, the null hypothesis is rejected. Comparison of different categories of direct composite resins revealed that all materials became rougher after simulated toothbrushing. Different levels of wear occurred according to filler size and distribution. In general, nanofilled systems and the Ormocer-based resin showed better performance than the microhybrid and conventional organic matrix composites. This comparison can be helpful to predict the performance of these materials under clinical service.

\section{ACKNOWLEDGMENTS}

This study was performed by G.U.O. as fulfillment of her Master's degree research that was supported by grant 136375/2006-5 from CNPq (Conselho Nacional de Desenvolvimento Científico e Tecnológico), Brazil. Authors are also thankful for 3M ESPE, Voco, Dentsply, Tokuyama Dental Corporation and Vigodent S/A Produtos e Comércio for donation of the tested products.

\section{REFERENCES}

1- Balooch M, Habelitz S, Kinney JH, Marshall SJ, Marshall GW. Mechanical properties of mineralized collagen fibrils as influenced by demineralization. J Struct Biol. 2008;162:404-10.

2- Bottenberg P, Jacquet W, Alaerts M, Keulemans F. A prospective randomized clinical trial of one bis-GMA based and two ormocerbased composite restorative systems in class II cavities: five-year results. J Dent. 2009;37:198-203.

3- Cilli R, Mattos MC, Honorio HM, Rios D, Araujo P, Prakki A. The role of surface sealants in the roughness of composites after a simulated toothbrushing test. J Dent. 2009;37:970-7.

4- Cunha LG, Alonso RCB, Santos PH, Sinhoreti MAC. Comparative study of the surface roughness of Ormocer-based and convencional composites. J Appl Oral Sci. 2003;11:348-53

5 - Davis N. A nanotechnology composite. Compend Contin Educ Dent. 2003;24:662-70.

6- Duke ES. Has dentistry moved into the nanotechnology era? Compend Cont Educ Dent. 2003;24:380-2.

7- Friebel M, Povel K, Cappius HJ, Helfmann J, Meinke M. Optical properties of dental restorative materials in the wavelength range 400 to $700 \mathrm{~nm}$ for the simulation of color perception. J Biomed Opt. 2009;14:054029.

8- Garcia FC, Wang L, D'Alpino PH, Souza JB, Araújo PA, Mondelli RF. Evaluation of the roughness and mass loss of the flowable composites after simulated toothbrushing abrasion. Braz Oral Res. 2004;18:156-61.

9- Hosseinalipour M, Javadpour J, Rezaie H, Dadras T, Hayati NA. Investigation of mechanical properties of experimental Bis-GMA/ TEGDMA dental composite resins containing various mass fractions of silica nanoparticles. J Prosthodont. 2010;19:112-7.

10- Ilie N, Hickel R. Investigations on mechanical behaviour of dental composites. Clin Oral Investig. 2009;13:4227-38.

11- Leinfelder KF, Beaudreau RW, Mazer RB. An in vitro device for predicting clinical wear. Quintessence Int. 1989;20:755-61.

12- Leprince J, Palin WM, Mullier T, Devaux J, Vreven J, Leloup G. Investigating filler morphology and mechanical properties of new low-shrinkage resin composite types. J Oral Rehabil. 2010;37:364-76.

13- Lu H, Lee YK, Oguri M, Powers JM. Properties of a dental resin composite with spherical inorganic filler. Oper Dent. 2006;31:73440.

14- Mahmoud SH, El-Embaby AE, AbdAllah AM, Hamama HH. Two-year clinical evaluation of ormocer, nanohybrid and nanofill composite restorative systems in posterior teeth. J Adhes Dent. 2008;10:315-22.

15- Mitra SB, Wu D, Holmes BN. An application of nanotechnology in advanced dental materials. J Am Dent Assoc. 2003;134:138290.

16- Mondelli RFL, Azevedo JF, Francisconi PA, Ishikirama SK, Mondelli J. Wear and surface roughness of bovine enamel submitted to bleaching. Eur J Esthet Dent. 2009;4:396-403.

17- O'Brien WJ, Yee J Jr. Microstructure of posterior restorations of composite resin after clinical wear. Oper Dent. 1980;5:90-4. 
18- Palaniappan S, Bharadwaj D, Mattar DL, Peumans M, Van Meerbeek B, Lambrechts P. Three-year randomized clinical trial to evaluate the clinical performance and wear of a nanocomposite versus a hybrid composite. Dent Mater. 2009;25:1302-14.

19- Papadogiannis DY, Lakes RS, Papadogiannis Y, Palaghias $G$, Helvatjoglu-Antoniades $M$. The effect of temperature on the viscoelastic properties of nanohybrid composites. Dent Mater. 2008;24:257-66

20- Prakki A, Cilli R, Mondelli RF, Kalachandra S. In vitro wear, surface roughness and hardness of propanal-containing and diacetyl-containing novel composites and copolymers based on bis-GMA analogs. Dent Mater. 2008;24:410-7.

21- Prakki A, Tallury P, Mondelli RF, Kalachandra S. Influence of additives on the properties of Bis-GMA/Bis-GMA analog comonomers and corresponding copolymers. Dent Mater. 2007;23:1199-204.
22- Sideridou ID, Karabela MM. Effect of the amount of 3-methacyloxypropyltrimethoxysilane coupling agent on physical properties of dental resin nanocomposites. Dent Mater. 2009;25:1315-24.

23- Turssi CP, Ferracane JL, Vogel K. Filler features and their effects on wear and degree of conversion of particulate dental resin composites. Biomaterials. 2005;26:4932-7.

24- Turssi CP, Magalhães CS, Serra MC, Rodrigues Júnior AL. Surface roughness assessment of resin-based materials during brushing preceded by $\mathrm{pH}$-cycling simulations. Oper Dent. 2001;26:576-84.

25- Wang L, Garcia FC, Amarante de Araújo P, Franco EB, Mondelli RF. Wear resistance of packable resin composites after simulated toothbrushing test. J Esthet Restor Dent. 2004;16:303-15. 